\title{
The effects of alcohol on semantic and phonetographic generalization'
}

\section{MICHAEL LEVY AND PATRICK H. MURPHY, III}

UNIVERSITY OF FLORIDA

One group of normal college males was given a moderate amount of alcohol prior to conditioned discrimination training of a voluntary response. A control group was given a placebo drink. The Placebo Ss later showed the usual superiority of semantic over phonetographic generalization. Alcohol completely reversed this relationship.

The purpose of the present experiment was to test the hypotheses that alchohol would increase the amount of phonetographic generalization (PG) and decrease the amount of semantic generalization (SG) found in normal adults. It has been known for some time (Riess, 1946) that young children display more generalization to words phonetographically related to CS words than to those semantically related, and that in normal adults the opposite trend appears. This reversal in trend is usually explained in terms of the growth of inhibitory tendencies toward $P G$ with the development of strong language habits. The explanation is difficult to test directly, but two recent findings lend some indirect support. Schwartz (1960) found that normal adults given injections of chloral hydrate show, in the drowsy state, more PG than SG. Peastral (1961) observed that certain adult schizophrenics, characterized by poor inhibitory control, also evidenced the child-like pattern of generalization.

If, in fact, the orthogonality in generalization between children and adults is due to the latter's inhibiting phonetographically mediated responses, then presenting an inhibition-reducing stimulus to adults should increase the occurrence of $P G$ and perhaps decrease the frequency of SG. The inhibition-reducing stimulus selected for use in the present experiment was ethyl alcohol (Hetherington \& Wray, 1964; White, 1956).

\section{Apparatus}

\section{METHOD}

The $\mathrm{S}$ sat in a sound-shielded room about $5 \mathrm{ft}$. from an 11 by $18 \mathrm{in.} \mathrm{screen.} \mathrm{Beneath} \mathrm{the} \mathrm{screen} \mathrm{was} \mathrm{a} \mathrm{panel}$ reading "PRESS" which, when illuminated by a $7-1 / 2 \mathrm{w}$ bulb, was the UCS. The conditioned(CS) and generalized (GS) words were projected onto the screen from E's room by an automatic slide projector. Key pressing responses (Kurcz, 1964) were detected by a Grass strain gauge rigidly mounted to S's chair desk, and were amplified and recorded by Grass low level dc amplifiers and Model 5 polygraph.

Procedure

Approximately two months prior to the beginning of the experiment, a "personality" questionnaire was administered to the Ss during their regularly scheduled class. The questionnaire contained 56 items from the
MMPI and nine new items related to the consumption of alcohol. Two Ss who in their responses to the critical items evidenced qualms against the taking of alcohol were automatically assigned to the control condition.

Upon entering the experimental room, Ss in the Placebo group were given a drink (Hetherington \& Wray, 1964) consisting of $300 \mathrm{cc}$ "7-Up," $30 \mathrm{cc}$ concentrated lemon juice, and $5 \mathrm{cc}$ peppermint extract. To these ingredients, reagent ethyl alcohol ( $\mathrm{cc}=.35$ by body weight in lbs.) was added for the Alcohol group. The $E$ then reappeared and told them, essentially, that they had to learn to anticipate the onset of the "PRESS" light when the correct words appeared by depressing the strain gauge.

Ten trials of conditioned discrimination followed, during each of which the following eight words were presented in random order: male, buy, sea, plain, close, coarse, won, and weak. For each pair of Alcohol and Placebo Ss, a different subset of four of these words (CS+) was consistently reinforced. The remaining words (CS-) were never reinforced. The CS (and GS) words lasted $2.0 \mathrm{sec}$., the UCS lasted $0.5 \mathrm{sec}$. , and the CS-UCS interval was $1.5 \mathrm{sec}$. The intertrial interval lasted about $2.5 \mathrm{sec}$.

In order to allow the alcohol to be further assimilated and to reduce rehearsal, all Ss then spent $20 \mathrm{~min}$. performing a cancellation task. Thereafter, generalization was measured during experimental extinction. The four CS+ and CS- words were each presented twice and one synonym (man, purchase, ocean, simple, shut, rough, overcome, fragile), one antonym (female, sell, land, fancy, open, smooth, lost, strong) and one homonym (mail, by, see, plane, clothes, course, one, week) of each CS word were shown. The orders of presentation of the 40 words were random for each pair of Ss subject to the restriction that in each 10 word series, four CS and two each of the other three classes of words appeared. Subjects

Thirty-eight male undergraduates at the University of Florida served as Ss. Except for the restriction that all Ss in the Alcohol group had to be over 21 years of age and had to have responded appropriately to the critical items on the "personality" questionnaire, Ss were unsystematically assigned to the two groups. One $S$ in the Placebo group misunderstood the instructions and his data were discarded.

Acquisition

RESULTS

No significant differences among the Alcohol and Placebo groups' means during the acquisition period 
Table 1. Mean Generalization Indices

\begin{tabular}{lccc} 
Group & Synonym & Antonym & Homonym \\
\hline Alcohol $(\mathrm{N}=19)$ & $.02^{\mathrm{B}}$ & $.04^{\mathrm{B}}$ & $.66^{\mathrm{A}}$ \\
Placebo $(\mathrm{N}=18)$ & $.50^{\mathrm{A}, \mathrm{B}}$ & $.25^{\mathrm{A}}, \mathrm{B}$ & -.14 \\
\hline
\end{tabular}

Note: Means having common superscripts are not sionificantly different $(p<.05)$ as determined by Duncan Multiple Rance Test.

were observed: the groups, respectively, made an average of $88.9 \%$ and $91.0 \%$ anticipatory responses to the CSt and $8.7 \%$ and $8.6 \%$ to the CS- words. Performance in each group to the CSt and CS- words appeared to stabilize after about four trials.

Generalization

Responses to CS- words and words related to them were not statistically different in any comparisons, and will not be described here. The responses to CS+ words by each group during the generalization test were significantly fewer than at the end of acquisition (Alcohol group $t=3.79, d f=18, p<.01$; Placebo group $t=3.49$, $\mathrm{df}=17, \mathrm{p}<.01$ ). Because of this expected drop in performance, generalization was evaluated in terms of responsiveness to the CS words during the generalization test.

The mean generalization indices to the synonyms, antonyms and homonyms in each group is shown in Table 1. These were obtained by dividing the difference between number of responses to the GS+ and GS- words of each word class by the difference between the number of responses to $\mathrm{CS}+$ and $\mathrm{CS}-$ during generalization, after correcting for differential opportunities to respond, e.g., $2 \times$ (No. Rs to homonyms related to $\mathrm{CS}_{+}$ minus No. Rs to homonyms related to CS-) / (No. Rs to $\mathrm{CS}_{+}$minus No. Rs to $\left.\mathrm{CS}_{-}\right)$. Analysis of variance of the data summarized in Table 1 revealed nonsignificant differences in overall generalization by the two groups $(F=0.00, d f=1 / 35)$ and in generalization to the three word classes $(F=0.40, d f=2 / 70)$ but a significant interaction between the presence of alcohol and the word class $(F=5.36, d f=2 / 70, p<.001)$. In fact, almost $63 \%$ of the variance in the data was due to the joint effects of alcohol and word class. As noted in Table 1, a Duncan range test revealed that Ss given alcohol generalize more to homonyms than

\section{Erratum}

COPPOCK, H.W. GSR conditioning at a long CS-US interval mediated by S's counting behavior. Psychon. Sci., 1966, 1, 155-156-The article should have included references to what appear to have been the first reports of overt verbal mediation of conditioning: synonyms and that Ss given a placebo show the opposite tendency. It should also be noted that Ss given alcohol generalize more to homonyms than control Ss.

\section{DISCUSSION}

The data from the present experiment clearly show two crude, but opposed, generalization gradients. Normal adults given alcohol generalized more to homonyms than synonyms of the CS+ words, and matched control Ss showed the expected opposite trend. If, as White states, the action of alcohol "first touches the most recently evolved areas of the cerebral cortex which have a predominately inhibitory function" (p. 412) producing a general disinhibition, then there may be considerable merit to the position which describes a growth of phonetographic inhibition during the acquisition of linguistic habits .

It should be mentioned that, operationally, the present experiment was a classical conditioning one. The $\mathrm{CR}$, UCR, and UCS, however, bear little resemblance to those conventionally employed in conditioning laboratories in this country. They closely mirror those currently used in the Soviet Union where this procedure is named voluntary instructed conditioning.

\section{References}

Hetherington, E. Mavis, \& Wray, Nancy P. Aggression, need for social approval, and humor preferences. J. abnorm. soc. Psychol., $1964,68,685-689$.

Kurcz, Ida. Semantic and phonetographic generalization of a voluntary response. J. verbal Lcarn. verbal Behav., 1964, 3, 261-268.

Peastral, A. Studies in efficiency: Semantic generalization in schizophrenia. Unpublished Ph.D. dissertation, University of Pennsylvania, 1961.

Riess, B. F. Genetic changes in semantic conditioning. $J$. exp. Psuchol., 1946, 36, 143-152.

Schwartz, L. A. Conditioned reflexes to verbal stimuli. Vopr. Psikhol., 1960, 1, 86-98.

White, R. W. The abnormal personality. New York: Ronald Press, 1956.

\section{Note}

1. The authors wish to thank Miss Sharon Wright for her assistance in data collection. The use of The Psychophysiological Laboratory of W. B. Webb is appreciated. The research was supported in part by funds from The Graduate School, University of Florida. 